\title{
Claudine Gauthier, La décapitation de saint Jean en marge des évangiles. Essai d'anthropologie historique et sociale
}

Préface de Michel Tardieu. Paris, Publications de la Sorbonne, coll. « Homme et société », 41, Université Paris I - Panthéon-Sorbonne, 2012, $158 \mathrm{p}$.

\section{Pierre Lassave}

\section{CpenEdition} Journals

Édition électronique

URL : http://journals.openedition.org/assr/24545

DOI : $10.4000 /$ assr. 24545

ISSN : $1777-5825$

Éditeur

Éditions de l'EHESS

Édition imprimée

Date de publication : 30 décembre 2012

Pagination : 179

ISSN : 0335-5985

\section{Référence électronique}

Pierre Lassave, « Claudine Gauthier, La décapitation de saint Jean en marge des évangiles. Essai d'anthropologie historique et sociale », Archives de sciences sociales des religions [En ligne], 160 | octobre-décembre 2012, mis en ligne le 12 mars 2013, consulté le 21 septembre 2020. URL : http:// journals.openedition.org/assr/24545; DOI : https://doi.org/10.4000/assr.24545

Ce document a été généré automatiquement le 21 septembre 2020.

(c) Archives de sciences sociales des religions 


\section{Claudine Gauthier, La décapitation de saint Jean en marge des évangiles. Essai d'anthropologie historique et sociale}

Préface de Michel Tardieu. Paris, Publications de la Sorbonne, coll. « Homme et société », 41, Université Paris I - Panthéon-Sorbonne, 2012, $158 \mathrm{p}$.

Pierre Lassave

\section{RÉFÉRENCE}

Claudine Gauthier, La décapitation de saint Jean en marge des évangiles. Essai d'anthropologie historique et sociale, Préface de Michel Tardieu. Paris, Publications de la Sorbonne, coll. « Homme et société », 41, Université Paris I - Panthéon-Sorbonne, 2012, 158 p. 
1 L'homme du désert vêtu de peau de chameau qui baptise Jésus dans le Jourdain a fini sa vie décapité. Le Baptiste fut d'abord mis en prison, à la demande d'Hérodiade, la femme du frère du « roi » Hérode Antipas, parce qu'il a déconseillé ce tétrarque de l'épouser en secondes noces. Séduit par Salomé, la fille d'Hérodiade qui dansait pour son banquet d'anniversaire, le roi céda à la demande de la danseuse en acceptant bien malgré lui de faire amener à la belle la tête du Baptiste sur un plateau. Cet épisode aussi scabreux que sanglant s'intercale discrètement dans les évangiles synoptiques entre baptême et prédication de Jésus. Contre l'avis de Renan qui y voyait un trait d'histoire, les exégètes ont depuis lors renvoyé cette vignette à une légende ornementale et superfétatoire.

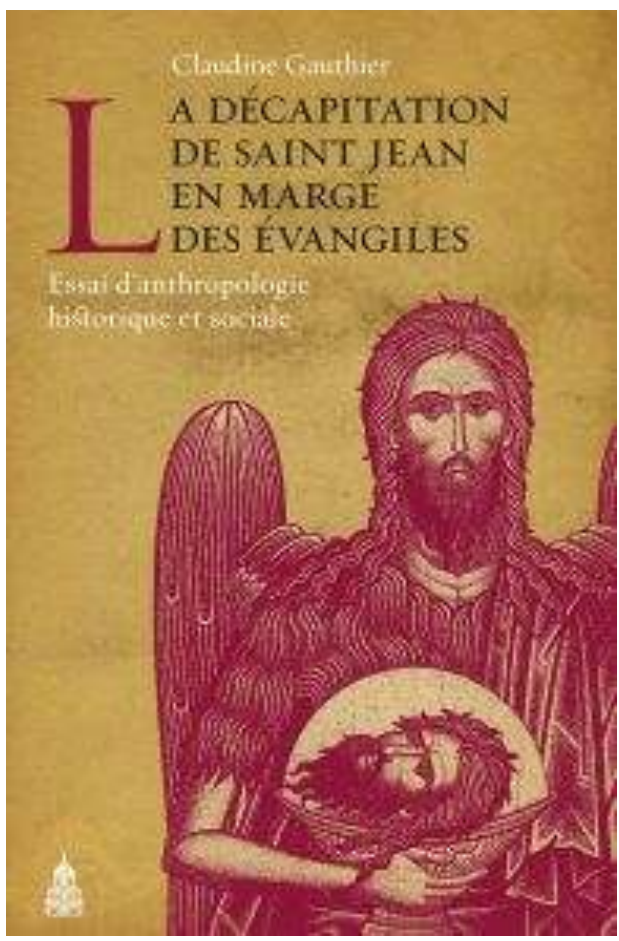

Pourtant elle est à l'origine

d'innombrables commentaires, récits, images et cultes populaires depuis deux millénaires. Dans cet essai qui fait suite à une première exploration de ces traditions (ASSR, Bulletin bibliographique, 148, 2009), Claudine Gauthier nous plonge dans un écheveau de formes et de sens en tentant d'en dénouer quelques fils : "Dépouille mortelle démembrée, tête coupée qui parle, garante du bon passage dans l'au-delà et libératrice du condamné à mort, sont des caractéristiques qui, à première vue, semblent fonctionner comme autant d'unités disparates. Elles trouvent pourtant un trait d'union en appartenant, toutes, à cet important ensemble que représente le folklore chrétien de la mort de Saint-Jean-Baptiste. Mais le travail de l'ethnologue ne s'arrête pas là. Il lui importe également, et peut-être surtout, de montrer que chacune de ces traditions n'est pas issue de ce que nous pourrions appeler la fantaisie populaire, mais qu'au contraire les éléments présents dans ces croyances comme dans les cultes ou institutions qui y sont associés forment un système cohérent au regard du milieu culturel dont ils sont issus » (p. 26-27).

2 L'auteur avait précédemment attiré l'attention sur les origines iraniennes des traditions du banquet anniversaire que l'on retrouve également dans le célèbre livre d'Esther, et aussi sur le caractère épileptique de la danse de Salomé au vu de ses vitraux, sur la dimension sacrificielle sinon anthropophagique de la tête portée sur un plateau ou encore sur la gémellité entre le Précurseur baptiste et le Messie crucifié. L'exploration se poursuit ici à travers les figures du démembrement du saint, de son chef flottant, et de la bonne mort que son martyre assure. À nouveau l'enquête érudite exhume des traditions perses par lesquelles le sciage du prophète Isaïe se retrouve dans une variante chiite du banquet sacrificiel dont l'issue fatale fait également lien avec le sciage égyptien d'Osiris enkysté dans un cèdre. Mais elle met surtout ces récits de coupures franches en correspondance avec la fête sicilienne du Muzzuni («tranché ») qui se tient le 24 juin à la Saint-Jean-Baptiste à Alcara Li Fusi, village situé dans la 
province de Messine. Ce muzzuni est une cruche tranchée au col dans laquelle les habitants plantent une gerbe d'orge issue d'un "jardin d'Adonis ", culture hâtive semée précocement en une dizaine de jours avant la fête. Habillés pour la circonstance d'un foulard coloré et ornés de bijoux, les muzzuna sont sortis et promenés en musique dans le village à la nuit de la Saint Jean, donc après une journée chargée, scandée par la messe célébrant la nativité du saint, par la tournée dans le village du saint la tête coupée à ses pieds, puis (autrefois) par les sauts au-dessus du feu scellant entre autres des fiançailles spirituelles entre jeunes gens (pratique du compérage maintenue). On ne peut seulement qu'évoquer ici quelques éléments très partiels d'un ensemble rituel aux variantes nombreuses associant traditions païennes, chrétiennes, grecques, égyptiennes et perses dont l'ethnographe révèle la cohérence. Cruche tranchée et chef d'orge apparaissent ainsi faire sens avec la coupure et le recollement entre compères comme avec la mort et la résurrection des prophètes dans une chaîne qui relie Isaïe, Élie, Zacharie, Jean jusqu'au Messie Jésus. Mais l'analyste se place à l'écart de toute tentation structurale et s'empresse d'aborder dans les chapitres suivants d'autres agencements symboliques.

3 Ainsi de l'eau et du feu que la tête du saint décollé associe : eau baptismale et feu de la fête, tête flottante sur la mer au lever du jour et qui parle du fond des puits, bûcher d'ossements du corps démembré dont les cendres retournent à la mer. À ces correspondances larges qui s'étendent du Nil antique à l'Asie Mineure s'articule à nouveau un rite local qui laisse quelques traces, celui du culte de saint Grat dans la Vallée d'Aoste, un saint protecteur qui recueillit au v $v^{\mathrm{e}}$ siècle au fond d'un puits la tête du Décollé et dont l'hagiographie est redevable à la Maison de Savoie plutôt qu'au clergé séculier. Hormis la Vallée d'Aoste, la trace spatiale du saint régional se perd comme l'atteste l'exploration de l'ethnographe jusque dans le comté de Nice.

4 Après l'espace, le temps : comment se fait-il qu'après la fête de la nativité du saint au solstice d'été (24 juin), celle de sa décollation se célèbre le 29 août? Parcourant les diverses premières traditions qui relatent les péripéties de la tête perdue et retrouvée du saint, l'enquête découvre que selon le calendrier alexandrin le 29 août se place à la césure entre deux années calendaires. La décapitation colle pour ainsi dire avec la célébration du nouvel an byzantin comme nouvelle tête à l'instar du Rosh ha-Shanah (" chef de l'an ») judaïque ou du Janvier-Janus romain. Mais la césure entre deux années comme entre deux mondes n'en est pas moins passage orienté dans une certaine direction. C'est ce que montre le dernier chapitre qui s'immisce dans les confréries de Saint-Jean décollé à la fin du Moyen Âge dont les membres accompagnent tout condamné à mort pour lui assurer le meilleur passage vers l'au-delà.

Confrérie secrète et à recrutement strictement local et bourgeois, la Compagnie des Noirs de Florence s'est ainsi formée à Florence au xiv ${ }^{e}$ siècle pour assister le condamné dans ses derniers jours, le conduire au repentir, recueillir son dernier souffle, lui donner une sépulture chrétienne. Un rituel de pénitence réglé sous l'égide des deux grands jumeaux figurés sur ces tablettes dévotionnelles à deux faces, l'une représentant à l'avers le Décollé, l'autre au revers le Crucifié, effigies que le pénitent noir encagoulé met en face du condamné jusqu'au dernier instant. Le lecteur peut s'étonner que dans l'analyse du rite rien ne transparaisse de l'étape finale où les pénitents recomposent soigneusement le corps du condamné éventuellement démembré en cas de décapitation, même si la plupart des exécutions de peine capitale semblent avoir été par pendaison. Mais la confrérie peut aussi conduire l'enquête 
jusqu'à l'obtention de la grâce du condamné. L'institution pénitente a essaimé dans les villes italiennes, notamment à Rome où la titulature johannique est associée à celle de la Vierge de Miséricorde, patronne des condamnés et des pestiférés. Association que l'on retrouve chez les pénitents noirs de Nice qui prononçaient encore au xix ${ }^{\mathrm{e}}$ siècle la grâce éventuelle du condamné le 29 août. Passeur de la vie à la mort et à la vie éternelle, saint Jean semble avoir trouvé dans ces institutions pénitentes du nord de la Méditerranée le plateau social de sa tête psychopompe.

Dans un épilogue en guise de conclusion, Claudine Gauthier renoue les divers fils de l'écheveau d'images, de rites, de croyances et d'institutions qu'elle a mis au jour en marge de la figure baptismale de Jean et à rebours d'une exégèse savante qui déniait toute valeur à sa décapitation. Elle insiste sur l'intégration de traditions de divers lieux et époques qu'opèrent des rituels populaires comme celui de la fête du Muzzuni qui résiste au temps et au mépris de l'Église. Elle souligne également que le folklore relatif à saint Jean décollé ne peut se réduire au schème bien connu de la christianisation d'anciens rites païens. Ainsi de saint Grat que l'on a vu naître avec sa propre légende alimentée par la Maison de Savoie pour d'évidents intérêts territoriaux. De même, l'institution urbaine des pénitents noirs a-t-elle fait de la tête de saint Jean le symbole du passage entre les mondes qu'elle assure de son assistance discrète. Bien d'autres traditions se greffent sur ce chef flottant et psychopompe, ne serait-ce que celle du roman arthurien où la quête de l'épée qui a tranché la gorge du saint conduit jusqu'au Graal. Dernières lignes qui plantent peut-être le décor merveilleux de nouvelles enquêtes ethnographiques. En tout état de cause, la préface de Michel Tardieu, professeur honoraire au Collège de France, offre un modèle d'érudition consommée à la quête du sang bouillonnant des prophètes tels Jean ou Zacharie à travers la chaîne lumineusement reconstituée des traditions arabes pré et postcoraniques.

Dans l'attente donc de nouvelles découvertes, on ne peut que saluer les précieux points de repère qu'apporte ce bel essai de Claudine Gauthier immergée dans les arcanes des traditions populaires échafaudées sur deux millénaires autour d'une étrange tête de saint. Certes le lecteur épris de systèmes et de structures risque de n'y trouver que du matériau semi-traité. Mais on y voit là comme une réserve implicite de l'auteur face à toute schématisation. Pour faire image, on pourrait dire que cet essai reste plus ethnologique qu'anthropologique. Ce qui n'enlève rien, bien au contraire, à son apport de connaissance. Certes la quête des correspondances tend à mettre en avant les harmoniques au détriment des ambivalences, des contradictions et des anachronismes. De même, hormis l'intention sous-jacente de l'auteur de révéler tout un pan de l'imaginaire social, pour ne pas dire païen, trop longtemps caché par les institutions ecclésiales, le rapport du sujet à l'objet de connaissance reste dans la pénombre. Mettre au jour les raisons de cette investigation au long cours au même titre que les diverses expériences ethnographiques suscitées et vécues de la Sicile au Comté de Nice, en passant par Aoste, Florence et Rome, aurait sans doute aidé le lecteur à mieux saisir la teneur plus ou moins transitoire, définitoire ou originale de ses résultats. Autre bémol, mais de détail formel : la riche matière accumulée au fil des pages, ne transparaît pas dans la table des matières expurgée des sous-titres pertinents qui animent le texte. 